\title{
Investigation and Analysis of Beijing Olympic Forest Park Tourism Interpretation System
}

\author{
Lingkui $\mathrm{Pu}{ }^{1, \text { a }}$, Qun Zhao ${ }^{2,3,4, b, *}$, Tao Guan ${ }^{2, c}$ \\ ${ }^{1}$ Beijing badaling forest farm, Beijing 102101, China \\ ${ }^{2}$ Department of landscape architecture, Beijing University of Agriculture, Peking, Beijing 102206, \\ China \\ ${ }^{3}$ Beijing Rural Landscape Planning and Design Engineering Technology Center, Peking, Beijing \\ 102206, China
}

${ }^{4}$ Beijing Laboratory of Urban and Rural Ecological Environment, Peking, Beijing 100083, China.

apulingkui@163.com, b869574897@qq.com, cguantao@bua.edu.cn

Corresponding author: Qun Zhao

\begin{abstract}
Keywords: Tourism interpretation system; Beijing Olympic Forest Park; Independent interpretation; Leading interpretation
\end{abstract}

\begin{abstract}
In this paper, the author takes the Olympic forest park as the research object and investigates the Olympic forest park tourism interpretation system through the study of the sampling survey of 300 visitors inquired by some related problems. The aim which the author examined is giving some improve mental measures and providing some guidance for other forest park of Beijing, according to the present situation of Olympic forest park tourism interpretation system and the willing of the 300 respondents. The study found that the independent interpretation system is not perfect and the leading interpretation system has some deficiencies. It needs to improve some aspect certainly, although tourists pretty satisfy the whole system of the park which a stream of visitors came here everyday. The author proposes some suggestions at the end of the article, and hopes to consolidate and improve the satisfaction and loyalty of tourists to the scenic spot.
\end{abstract}

\section{Introduction}

Forest park, with its good forest landscape and ecological environment, using a variety of functions of forest [1], provides people with a set of a certain scale tour, vacation, recreation, healthcare facilities, scientific education and cultural entertainment in one place. Forest park interpretation system can use all kinds of material and media activities, pass for specific information on forest park visitors a communication service process. It is a kind of informal education activities, and recreation in a rich tourists experience at the same time, to convey knowledge [2-7].

\section{Beijing Olympic forest park tourism explanation system survey}

About 300 tourists are visited. About $34.5 \%$ of tourists is to relax and relief stress for the purpose of tourists to the Olympic forest park, there are $28.7 \%$ of visitors have a happy time with family and friends, easy visitors to the park's main purpose is to do sports and parenting [8-13].

\subsection{Frequency of visitors using the Olympic forest park's travel commentary}

After investigating 300 respondents in the park to visit during mainly take the way of explanation for the independent browsing placards way, external guide explanation and ask passers-by also took part. In the absence of an in-house tour guide, it is the park's top priority (Table 1). 
Table 1 Frequency of visitors using the Olympic forest park's travel commentary

\begin{tabular}{|c|c|c|c|}
\hline \multirow{2}{*}{ Explanation way } & \multicolumn{2}{|c|}{ response } & \multirow{2}{*}{$\begin{array}{c}\text { Case } \\
\text { percentage }\end{array}$} \\
\cline { 2 - 4 } & $\mathrm{N}$ & percentage & $72.2 \%$ \\
\hline \multirow{2}{*}{$\begin{array}{c}\text { Browse the explanation card by itself } \\
\text { The tour guide commentary }\end{array}$} & 208 & $51.1 \%$ & $36.5 \%$ \\
\cline { 2 - 4 } Consulting passers-by & 105 & $25.8 \%$ & $31.3 \%$ \\
\hline Other way & 90 & $22.1 \%$ & $1.4 \%$ \\
\hline total & 4 & $1.0 \%$ & $141.3 \%$ \\
\hline
\end{tabular}

2.2 The importance of self-guided commentary CARDS (Table 2)

Table 2 The importance of a commentary card

\begin{tabular}{|c|c|c|c|c|}
\hline & frequency & percentage & $\begin{array}{c}\text { Effective } \\
\text { percentage }\end{array}$ & $\begin{array}{c}\text { cumulative } \\
\text { percentage }\end{array}$ \\
\hline Very important & 85 & 28.3 & 28.3 & 28.3 \\
\cline { 2 - 5 } important & 180 & 60.0 & 60.0 & 88.3 \\
\hline $\begin{array}{c}\text { general } \\
\text { Not important } \\
\text { total }\end{array}$ & 34 & 11.3 & 11.3 & 99.7 \\
\cline { 2 - 5 } & 1 & .3 & .3 & 100.0 \\
\hline
\end{tabular}

$74.7 \%$ of the respondents to the Olympic forest park placards evaluation is satisfactory, the remaining $25.3 \%$ think generally, not dissatisfied and very dissatisfied with the situation. This is in line with the park's 5A status. In the end, the Olympic forest park has done a good job in explaining card (Table 3).

Table 3 Need to improve explanation card

\begin{tabular}{|c|c|c|c|}
\hline & \multicolumn{2}{|c|}{ response } & Case \\
\cline { 2 - 3 } & $\mathrm{N}$ & percentage & percentage \\
\hline Improve scenic guide & 144 & $15.8 \%$ & $48.0 \%$ \\
\hline Improve road sign & 164 & $17.9 \%$ & $54.7 \%$ \\
\hline Improve Environmental placards & 202 & $22.1 \%$ & $67.3 \%$ \\
\hline Improve scenic spot placards & 92 & $10.1 \%$ & $30.7 \%$ \\
\hline Improve Regulations billboard & 56 & $6.1 \%$ & $18.7 \%$ \\
\hline Improve Resource protection token & 78 & $8.5 \%$ & $26.0 \%$ \\
\hline Improve Facilities sign & 107 & $11.7 \%$ & $35.7 \%$ \\
\hline Improve safety sign & 71 & $7.8 \%$ & $23.7 \%$ \\
\hline total & 914 & $100.0 \%$ & $304.7 \%$ \\
\hline
\end{tabular}

2.3 Evaluation of the overall interpretation system of the Olympic forest park (Table 4)

Table 4 Evaluation of the overall interpretation system

\begin{tabular}{|c|c|c|c|c|c|}
\hline \multicolumn{2}{|c|}{} & frequency & percentage & $\begin{array}{c}\text { Effective } \\
\text { percentage }\end{array}$ & $\begin{array}{c}\text { cumulative } \\
\text { percentage }\end{array}$ \\
\hline \multirow{4}{*}{ satisfy } & satisfy & 36 & 12.0 & 12.0 & 12.0 \\
\cline { 2 - 6 } & satisfy & 188 & 62.7 & 62.7 & 74.7 \\
\cline { 2 - 6 } & general & 72 & 24.0 & 24.0 & 98.7 \\
\cline { 2 - 6 } & Not satisfy & 4 & 1.3 & 1.3 & 100.0 \\
\cline { 2 - 6 } & total & 300 & 100.0 & 100.0 & \\
\hline
\end{tabular}


The results show that $74.7 \%$ of visitors to the Olympic forest park, the overall system is satisfied with, think generally accounts for $24 \%, 1.3 \%$ of tourists are not satisfied with park interpretation system (Table 5).

Table 5 Need to improve explanation card

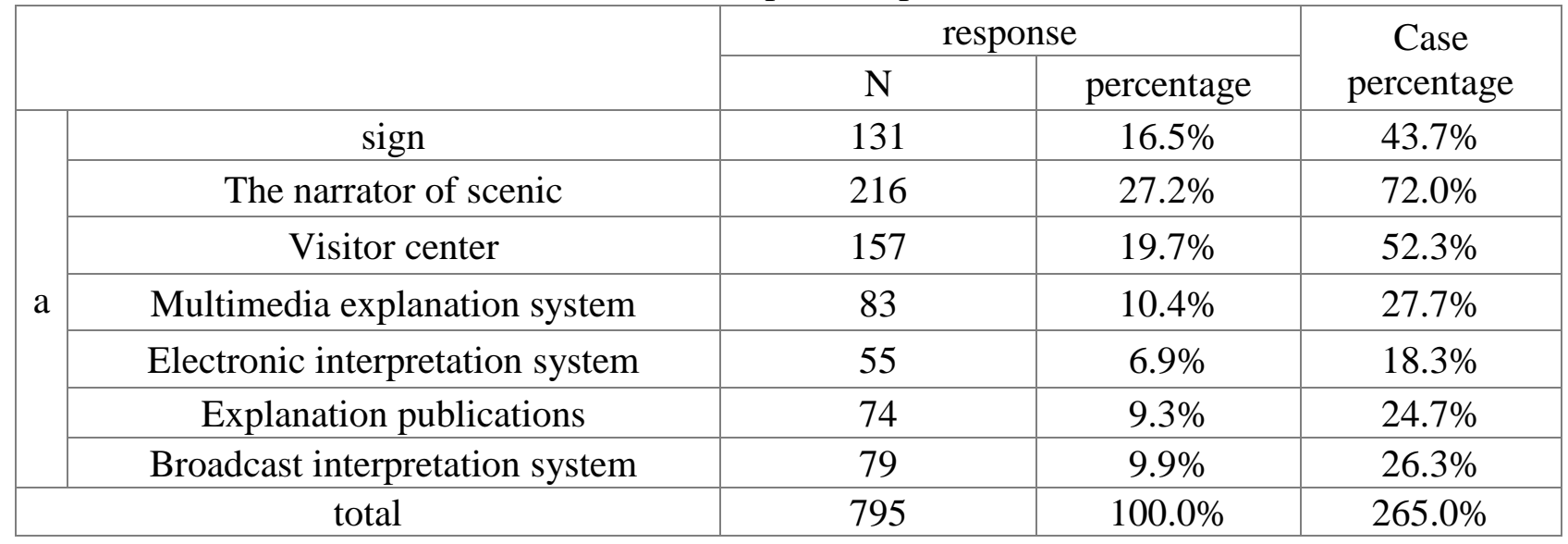

\section{Advice with the guidance in the park}

Standardize the interpretation of staff in the park and train them regularly. Reasonable layout and design guide commentary content to avoid the monotony of the commentary content. Only in this way can visitors be knowledge and understanding of the park [14-18].

\subsection{Advice with self-guided commentary in the park}

Self-guided narration should focus on people-oriented, and reinforce the appeal of the content of commentary. The explanation system must be people-oriented, and it should be considered for tourists. The height, distance, Angle, location, size, color, etc. Are all put in place for the visitors.

\subsection{Advice with the park's internal travel commentary system}

To establish the system for maintaining and updating the interpretation system and setting up the evaluation and improvement system of the commentary system. The evaluation and improvement of the commentary system is also the top priority of the forest park. Only set up the evaluation mechanism can know where their hand was not very ideal, which is to improve and further opportunity, can let more visitors enjoy the pleasure of forest park, have nice experience to visit.

\section{Conclusion}

Through Beijing Olympic forest park scenic area interpretation system of fieldwork and survey analysis, understand the current status, advantages and disadvantages of the park interpretation system and the existing problems, the deficiency existed in the scientific analysis and gives the corresponding solutions. It gives some guidance to the future development of the Olympic forest park. Beijing Olympic forest park will be able to better serve tourists and improve the visibility and reputation of the park according to the advice.

\section{Acknowledgements}

Thanks to Beijing rural landscape planning and design engineering technology center Project Support: Science and technology innovation service ability construction- Urban and rural ecological environment Beijing laboratory construction (PXM2017-014207-000037). 


\section{References}

[1] Zhang liing, zhao liming. The construction of the national forest park tourism explanation system. Journal of northwest agricultural science and technology university,2006,6(2):88-92.

[2] Liang ding, zeng qingdong. Research on stability and sustainable development in forest park. Tropical forest,2011,39(2):7-9.

[3] Li bifang. Forest landscape function of forest park. Subtropical plant science,2009,38(2):85-88.

[4] He lifang. The ecological culture of the forest park, education value. Hunan forestry technology,2011,38(2):78-80.

[5] Wu bing, jinhua, zhang li. Research on travel commentary system. In Beijing. Cultural geography, 1999,14(2):27-29.

[6] Xiao tingting. Environmental explanation system of forest park. Journal of guangxi economic management cadre college,2013,3:63-66.

[7] Wu bing, jinhua, zhang li. Planning and management of travel commentary system. Tourism journal,1999,1:44-46.

[8] Yang cai-gan, guo jianying, the urban forest park tourism interpretation study in the urban forest park, for example, the nanjing golden mountain forest park, the journal of the northwest forestry college,2014,29(3):221-226.

[9] Zhao jianchang. The construction of tourism explanation system in baoji jintai forest park. Jiangxi agricultural journal,2011,23(4):186-188.

[10] Donghala, a travel commentary system, is an example of the liuyang road.2003,3(18):14-17.

[11] Yuxiying.The improvement of the travel commentary system in the forest park of yunmeng , national forest park.2005,6:554-556.

[12] Zhang bo. Based on the means - objective theory of the humanistic travel explanation system. 2011,5:143-147.

[13] Jiang hongying and Yang meixia. The status analysis and countermeasures of the travel commentary system in zhangiajie. Journal of dalian nationalities college,2006,4:123-125.

[14] Zhou kehua, luo mingchun and Chen xiaoqing. The planning of the floating travel commentary system.2007,18(1):55--58

[15] Yu dezhen, Li helong power. The travel commentary system of forest park. Hunan forestry technology,2004,31(6):79-80.

[16] Zhao Ming. Construction of environmental interpretation system of national forest park based on SMRM. Journal of zhongnan forestry science and technology university,2012,6(3):12-15.

[17] Wang na. Perfect the forest park tour guide system. Technical advice guide, 2007,24:95.

[18] Ji liping. The planning of the tourist explanation system in the scenic area005,2:17-20. 